\title{
FITORREMEDIAÇÃO: PLANTAS COMO AGENTES DE DESPOLUIÇÃO?
}

FABIANE PINTO LAMEGO*

RIBAS ANTONIO VIDAL**

\begin{abstract}
Esta revisão teve como objetivo abordar aspectos da fitorremediação e sua aplicação para a descontaminação de áreas poluídas, decorrentes de atividades humanas. Foram discutidos os métodos de fitorremediação, os processos fisiológicos envolvidos, as propriedades das plantas utilizadas e sua relação com a biotecnologia, bem como vantagens e desvantagens dessa tecnologia. Atividades realizadas pelo ser humano como a industrialização e o uso de químicos na agricultura geram poluentes e a remoção dos compostos potencialmente tóxicos formados torna-se complexa, uma vez que existem diferentes classes e tipos de químicos. Outro aspecto que dificulta a recuperação de áreas contaminadas é o custo oneroso de métodos tradicionalmente utilizados para remoção dos poluentes. Deste modo, a fitorremediação vem despertando interesse mundial e apresenta potencial para uso no Brasil. Pesquisas científicas têm selecionado diversas espécies vegetais com potencial para limpeza de áreas contaminadas e a biotecnologia tem possibilitado a adequação da habilidade descontaminante de outras espécies.
\end{abstract}

PALAVRAS-CHAVE: FITORREMEDIAÇÃO; POLUIÇÃO AMBIENTAL; HERBICIDAS; METAIS PESADOS; PLANTAS HIPERACUMULADORAS.

* Engenheira Agrônoma, Doutoranda do Programa de Pós-Graduação em Fitotecnia, Universidade Federal do Rio Grande do Sul (UFRGS), Porto Alegre, RS (fabilamego@yahoo.com.br).

** Engenheiro Agrônomo, PhD em Weed Science, Professor do Departamento de Plantas de Lavoura, Faculdade de Agronomia, UFRGS, Porto Alegre, RS (ribas.vidal@ufrgs.br). 


\section{INTRODUÇÃO}

O lançamento de resíduos na atmosfera, na água ou no solo, caracteriza poluição ambiental (NASCIMENTO, 1996). A poluição do meio ambiente tornou-se, especialmente nas últimas décadas, assunto de interesse público que afeta tanto os países desenvolvidos como as nações em desenvolvimento.

O Brasil encontra-se entre os países maiores poluidores do mundo (GREENPEACE, 2006). Dejetos humanos e resíduos industriais saturam as redes de saneamento básico nas grandes cidades, contaminando águas e solos, assim como os gases liberados por veículos e fábricas poluem a atmosfera constantemente. O total de áreas contaminadas cadastradas, identificadas só no Estado de São Paulo, saltou de 255 em maio de 2002 para 1822 em novembro de 2006 (CETESB, 2007). Levantamento realizado pela Companhia de Tecnologia de Saneamento Ambiental daquele Estado apontou as atividades industriais e agrícolas, os depósitos de resíduos e postos de gasolina como as causas dessas contaminações. Outro exemplo de poluição são os resíduos industriais lançados em rios. Dentre esses, destacam-se os provenientes da indústria do couro (concentrada no Estado do Rio Grande do Sul) que gera cerca de 14 milhões de metros cúbicos de águas residuais por ano (COSTA, 2004).

A contaminação dos solos por metais pesados constitui outra forma de poluição grave, sendo considerados os poluentes ambientais que mais abalam a saúde pública. Os metais ocorrem naturalmente nos solos, mas quando somados aos efeitos das atividades humanas causam diversos danos. Como exemplo tem-se o cádmio, utilizado na manufatura de baterias e alguns biocidas, que ao entrar na cadeia alimentar pode resultar em lesões no fígado e problemas renais em seres humanos (BIOTECH, 2006).

As atividades realizadas pelo ser humano geram poluição e a remoção desses compostos potencialmente tóxicos do ambiente torna-se complicada, devido ao grande número de classes e tipos de compostos produzidos. Métodos para recuperação de áreas contaminadas já existem e compreendem o tratamento de águas industriais, escavação, incineração e remoção física de poluentes, dentre outros. Todavia, os dados da literatura apontam custos estimados entre US $\$ 25$ a 30 bilhões para a despoluição ambiental mundial (PLETSCH, CHARLWOOD e ARAÚJO, 1999). Nos Estados Unidos da América (EUA), anualmente, são gastos de US\$ 6 a 8 bilhões para limpeza de áreas poluídas (PILON-SMITS, 2005). Em países com recursos limitados, normalmente ocorre apenas o tratamento primário do poluente. O uso de tecnologias adequadas e com menor custo, ou seja, sistemas de tratamento com baixo consumo de energia e alto grau de eficiência tornou-se essencial. Neste contexto, a fitorremediação vem despertando o interesse mundial como alternativa para o tratamento de áreas poluídas a partir do uso de plantas. Seu custo atrativo, mais barato que os métodos convencionais de despoluição, atraiu a atenção de órgãos governamentais e das indústrias. Além disso, constitui excelente alternativa para evitar a intoxicação da população que vive em áreas contaminadas.

O objetivo desta revisão foi abordar aspectos da fitorremediação e sua aplicação para a limpeza de áreas poluídas decorrentes de atividades humanas.

\section{DEFINIÇÕES}

A fitorremediação constitui mercado que cresce anualmente nos EUA, na Europa e, mais recentemente, no Brasil. As companhias de consultoria ambiental já incluem a fitorremediação em seus pacotes de tecnologia (PILON-SMITS, 2005), a qual consiste no uso de plantas e seus associados (microbiota) para limpeza de ambientes poluídos. Nessa tecnologia são empregados processos naturais pelos quais as plantas e a flora microbiana presente na rizosfera degradam e seqüestram poluentes orgânicos e inorgânicos (RASKIN et al., 1994). Pesquisas científicas têm 
mostrado o potencial de diversas espécies de plantas para limpeza de áreas contaminadas e, com auxílio da biotecnologia, avanços vêm sendo obtidos na adequação de outras plantas para limpeza de áreas poluídas.

Os poluentes que contaminam ambientes podem ser classificados como orgânicos e inorgânicos. Poluentes orgânicos são aqueles produzidos pelo homem e causam danos aos organismos por serem tóxicos e alguns carcinogênicos. Esse tipo de poluente pode ser liberado no ambiente via derramamento de combustíveis e de solventes (tricloroetileno), ser decorrente de atividades militares (explosivos e armas químicas) e do uso de inseticidas, fungicidas, herbicidas e fertilizantes na agricultura, ou proveniente de resíduos industriais (químicos e petroquímicos) (PILON-SMITS, 2005). Poluentes orgânicos, dependendo de suas propriedades, podem ser degradados na zona radicular das plantas e quando absorvidos podem ser degradados, seqüestrados ou volatilizados pelas mesmas. Já, poluentes inorgânicos ocorrem como elementos naturais na crosta terrestre ou na atmosfera. Atividades humanas como mineração, industrialização e agricultura, por exemplo, promovem sua liberação no ambiente. Esses poluentes não podem ser degradados, mas sim fitorremediados via estabilização ou seqüestro nos tecidos de plantas que são tratadas posteriormente. Alguns exemplos de poluentes inorgânicos fitorremediados incluem macronutrientes (nitrato e fosfato, cromo, cobre e zinco) que são importantes para a constituição de enzimas em plantas, mas em níveis elevados nos solos tornam-se tóxicos. Outros exemplos são nutrientes não-essenciais às plantas como, cádmio, mercúrio e isótopos radioativos (PILON-SMITS, 2005).

\section{MÉTODOS DE FITORREMEDIAÇÃO}

Diferentes tecnologias de fitorremediação têm sido empregadas para a limpeza de áreas poluídas. Sistemas hidropônicos, ou rizofiltração, alcançaram sucesso. Sistemas "wetlands" têm sido opção viável no tratamento de esgoto doméstico e outros tipos de águas residuais em virtude de sua natureza simples, fácil operação e rentabilidade técnico-econômica (COSTA, 2004). Os primeiros experimentos com esse sistema foram realizados na Alemanha em 1952 (WILLIAMS, 1993) e continuam sendo eficientes. Nesses sistemas, as plantas cultivadas em tanques adsorvem sólidos suspensos, metais e patógenos. Além disso, promovem abrigo para o crescimento de microrganismos e servem de cobertura para sombreamento na água prevenindo a proliferação de algas (COSTA, 2004).

Trabalho realizado na Universidade de Campinas (Unicamp) evidenciou o potencial das espécies Pennisetum purpureum (capim-elefante), Brachiaria decumbens e Pennisetum graucum (milheto forrageiro), cultivadas em sistema de tanques para o tratamento de efluentes industriais de curtumes (COSTA, 2004). A concentração de cromo nas raízes de $B$. decumbens foi significativamente maior que a encontrada nas raízes do $P$. purpureum, no entanto, $P$. purpureum removeu significativamente mais cromo em virtude da sua grande massa radicular (COSTA, 2004).

Métodos baseados na interação planta-rizosfera incluem o plantio de árvores que devido ao seu denso sistema radicular podem ser utilizadas como barreira hidráulica (PILON-SMITS, 2005). As árvores criam fluxo de água ascendente na zona radicular e, desta forma, evitam a lixiviação ou a contaminação do ambiente por espalhamento horizontal do poluente. Populus ssp. em combinação com gramíneas têm demonstrado potencial para evitar a dispersão de poluentes. Populus sp. mantém fluxo ascendente na região da rizosfera, sendo muito eficiente e apresentando altas taxas de transpiração. Já as gramíneas evitam a dispersão e a lixiviação dos poluentes. Gramíneas não tendem a acumular poluentes inorgânicos em sua parte aérea como a maioria das dicotiledôneas, reduzindo assim o risco de exposição da vida selvagem a elementos tóxicos (DAWSON e EHLERINGER, 1991; MCCUTCHEON e SCHNOOR, 2003). 


\section{FITORREMEDIAÇÃO E PROCESSOS FISIOLÓGICOS}

Existem cinco tipos de fitorremediação baseados em processos fisiológicos das plantas: fitoestabilização, fitovolatilização, fitodegradação, fitoestimulação e fitoextração (PILON-SMITS, 2005). A fitoestabilização consiste no uso de plantas com o propósito de estabilizar os poluentes no solo, prevenindo perdas por erosão ou lixiviação. Para isso, processos como a precipitação do poluente na rizosfera por meio de humificação ou ligações covalentes irreversíveis são realizados promovendo a conversão do poluente para forma menos biodisponível. Também é posssível a liberação de $\mathrm{O}_{2}$ e demais compostos, imobilizando metais na região da rizosfera (PILON-SMITS, 2005).

Estudos demonstraram que a associação de plantas e microrganismos, como fungos micorrizas pode ter significante efeito na absorção de urânio pelas plantas (RUFYIKIRI, THIRY e DECLERCK, 2003; RUFYIKIRI et al., 2002). Micorrizas podem proteger o crescimento das plantas em solos com acúmulo de metais, aumentando a retenção dos metais nas raízes das plantas e reduzindo sua distribuição à parte aérea. Além disso, há a possibilidade de ligações entre micélios de fungos e metais pesados, como zinco e cádmio (JONER, BRIONES e LEYVAL, 2000). Portanto, micorrizas podem ser utilizadas na fitoestablização de metais nos solos, promovendo a restauração ecológica de locais poluídos por metais pesados.

A fitovolatilização é o processo no qual após absorção e incorporação no tecido da planta, os poluentes podem deixá-la na forma volátil. Esse tipo de limpeza de ambientes pode ser utilizado para compostos orgânicos voláteis como tricloroetileno (TCE) e para os poucos inorgânicos que podem existir na forma volátil, como selênio e mercúrio. Culturas como arroz, brócolis, couves e algumas outras plantas são capazes de volatilizar selênio (PILON-SMITS, 2005). Como a volatilização remove completamente o poluente do local na forma de gás, sem a necessidade de realizar a colheita da planta, a fitovolatilização mostra-se como tecnologia bastante atrativa. Todavia, o poluente tóxico emitido pelas plantas durante a fitovolatilização é lançado na atmosfera e poderia ser considerado fator de risco para nova fonte de poluição. Estudos realizados com selênio e mercúrio não demonstraram riscos para o ambiente de acordo com os níveis desses gases fitovolatilizados (LI et al., 2000).

$\mathrm{Na}$ fitodegradação, as plantas podem degradar poluentes orgânicos diretamente por suas próprias atividades enzimáticas. Esse tipo de processo é ideal para poluentes orgânicos que são móveis em plantas (como herbicidas, trinitrotolueno e TCE) e compreende a ação de complexos enzimáticos presentes nas plantas, como glutationas e citocromo P-450 monoxigenases. Apenas poluentes orgânicos podem ser fitorremediados via degradação. As enzimas agem sobre o poluente mineralizando-o completamente a compostos inorgânicos como, dióxido de carbono, água e $\mathrm{Cl}_{2}$ ou, ainda, degradando-o a intermediários estáveis que são armazenados na própria planta. A fitodegradação é geralmente atribuída à planta mas, em alguns casos, microrganismos endofíticos podem estar envolvidos (BARAC et al., 2004).

A degradação de poluentes orgânicos por microrganismos na rizosfera, estimulada pelas plantas, compreende o processo de fitoestimulação. Esse processo tem sido útil para a limpeza de ambientes contaminados por compostos orgânicos hidrofóbicos que não podem ser absorvidos pela planta, mas podem ser degradados por microrganismos como bifenilas policloradas (PCB) e outros hidrocarbonetos de petróleo (KAIMI et al., 2006).

A presença de micorrizas geralmente incrementa o crescimento da planta e favorece a dissipação de hidrocarbonetos de petróleo (GÜNTHER, DORNBERGER e FRITSCHE, 1996). Tal constatação pode ser explicada pelo estímulo à atividade microbiana (exsudatos de plantas que servem como fonte de carbono e nitrogênio, dentre outros, aumentam a atividade microbiana). $O$ crescimento radicular também abre a profundidade do solo para melhor infiltração de água e difusão de oxigênio. Entretanto, poucas pesquisas têm sido conduzidas sobre as relações entre o crescimento radicular das plantas, a atividade microbiana e a degradação de contaminantes (KAIMI et al., 2006). 
Foram conduzidos trabalhos visando examinar o potencial do azevém (Lolium multiflorum L.) na fitoestimulação de área contaminada com óleo diesel, avaliando a dissipação de hidrocarbonetos totais de petróleo (KAIMI et al., 2006). O azevém foi adotado como planta modelo pela sua habilidade de crescer em solos contaminados por óleo diesel, confirmada por experimentos preliminares. Esse tipo de poluição é complexa porque os contaminantes de petróleo podem ser fortemente adsorvidos na matéria orgânica de solo com taxa de dessorção muito baixa, causando a formação de resíduos ligados não-extraíveis. Os resultados obtidos demonstraram que a presença do azevém promove maior dissipação do óleo diesel quando comparado à ausência da planta. Também foi observada correlação positiva entre o comprimento radicular do azevém e a atividade microbiana no solo contaminado. Esses autores afirmaram que ajustes na fertilização e na densidade de plantio do azevém podem favorecer maior desenvolvimento radicular, auxiliando seu uso para fitorremediação (KAIMI et al., 2006).

Os herbicidas, em geral, sofrem degradação microbiana quando presentes nos solos. A degradação parcial da molécula do inibidor do fotossistema II em plantas (atrazina) por fungos como Aspergillus fumigatus e Rhizopus stolonifer foi constatada. A maioria das ações microbianas relatadas envolvem bactérias do gênero Rhodococcus, Nocardia, Bacillus e principalmente Pseudomonas, gênero bastante versátil com habilidade para degradar também 2,4-D (BEHKI e KHAN, 1986; BEHKI et al., 1993; LEVANON, 1993).

Trifloxissulfurom-sódico, herbicida recentemente registrado no Brasil, é aplicado em pósemergência inicial e vêm sendo amplamente utilizado nas culturas de algodão e cana-de-açúcar. Embora usado em baixas concentrações, o período de espera para o plantio de culturas sensíveis pode chegar a oito meses após sua aplicação. Esse fato pode limitar o emprego do produto nas áreas em que o agricultor cultiva, por exemplo, feijão no inverno (PROCÓPIO et al., 2005). Trabalho sobre o potencial de espécies vegetais na remediação do herbicida trifloxissulfurom-sódico em solos, utilizando o feijão como planta indicadora, constatou que Mucuna aterrima e Canavalia ensiformes foram capazes de reduzir a contaminação e permitir que o feijão tivesse melhor desenvolvimento nos solos pós-cultivo dessas espécies (PROCÓPIO et al., 2005). Estudos posteriores são necessários, todavia, é possível que o processo de fitoestimulação seja responsável pela redução no intervalo de segurança para o cultivo do feijão, acelerando a degradação do herbicida pela flora microbiana no solo.

A fitoextração, ou seja, a extração dos poluentes do solo e seu posterior acúmulo nos tecidos das plantas compreende espécies denominadas hiperacumuladoras. As plantas hiperacumuladoras são capazes de acumular um ou mais elementos inorgânicos em níveis até cem vezes maiores que outras espécies, crescendo sob as mesmas condições. Têm sido apontadas como acumuladoras de arsênio, cobalto, cobre, manganês, níquel, chumbo, selênio e zinco. Descobriu-se que Pteris vittata apresenta potencial para fitoextração de arsênio (MA et al., 2001).

Para a técnica de fitoextração fica clara a necessidade de colheita posterior da planta, contendo o poluente acumulado em seus tecidos, podendo o material colhido ser utilizado para propósitos não-alimentares. No caso de metais pesados quando a maior parte do metal estiver localizado na parte aérea das plantas, a colheita poderá ser realizada pelos métodos tradicionais de agricultura. Em geral, é necessário colher as plantas antes da queda das folhas ou antes da sua morte e decomposição para que os contaminantes não se dispersem ou retornem ao solo. Após a colheita, a biomassa das plantas fitoextratoras deverá ser processada para extração e recolhimento da maior parte dos metais. Se forem solos contendo níquel, zinco ou cobre, o valor do metal extraído pode incentivar a fitorremediação. $O$ volume ou o peso da biomassa podem ser reduzidos, alternativamente, por meio de processos térmicos, físicos, químicos ou microbiano. No caso da queima das plantas, por exemplo, a energia produzida representa valorização econômica do processo. As cinzas podem ser tratadas como minério, do qual pode ainda ser extraída a contaminação metálica (especialmente, cinzas enriquecidas com apenas um ou dois metais) (GRATÃO et al., 2005). 
O urânio (metal radioativo), amplamente disperso na crosta terrestre é considerado nãoessencial para as plantas. Sua distribuição, causada pelas atividades humanas, pode levar à contaminação de águas subterrâneas e solos superficiais. Riscos de absorção de urânio estão relacionados com câncer (radioatividade alfa) e efeitos colaterais sobre o sistema linfático, rins e fígado (CHEN et al., 2005). O uso de quelantes pode incrementar a mobilidade de metais no solo e formar complexos com metais, os quais reduzem as cargas positivas e afetam a disponibilidade dos metais às plantas (HUANG et al., 1998). Três espécies foram avaliadas por CHANG et al. (2005) quanto ao seu potencial para fitoextração de urânio em áreas contaminadas, influenciadas pelo uso ou não de ácido cítrico como quelante (Brassica chinensis var. oleifera, Brassica juncea, Brassica napus var. napus e Helianthus annus). Os autores afirmaram que Brassica juncea pode ser recomendada como espécie potencial para fitoextração de solos contaminados por urânio, devido ao elevado acúmulo na parte aérea (ideal para fitorremediação permitindo a coleta dessas plantas) e grande produção de biomassa quando comparada à maioria das hiperacumuladoras. A canola mostrou bom potencial fitorremediador por acúmulo maior do metal nas raízes. Já, o girassol acumulou pouca quantidade do metal na parte aérea. O uso de ácido cítrico como quelante é eficiente, mas o urânio disponível pode promover contaminação de águas subterrâneas.

\section{PROPRIEDADES DAS PLANTAS UTILIZADAS PARA FITORREMEDIAÇÃO}

Diferentes propriedades das plantas são importantes para a fitorremediação. Em geral, as seguintes características são favoráveis para a utilização de plantas como fitorremediadoras: crescimento rápido, elevada produção de biomassa, competitividade, vigor e tolerância à poluição. Plantas com essas características podem ser utilizadas como agentes de despoluição.

\section{A BIOTECNOLOGIA E A FITORREMEDIAÇÃO}

Muitas plantas hiperacumuladoras apresentam crescimento lento e baixa produção de biomassa. Há exceções como Alyssum bertolonii, acumuladora de níquel e testada em condições de campo (LI et al., 2003). Avanços têm sido obtidos com o auxílio da biotecnologia para contornar as limitações de plantas que se enquadram na categoria de hiperacumuladoras. Segundo PILONSMITS e PILON (2000) há duas linhas biotecnológicas que podem ser utilizadas para criar plantas ou adaptá-las à fitorremediação. O incremento de rotas metabólicas existentes em plantas, mediante superexpressão de genes responsáveis por enzimas interessantes aos processos de fitorremediação e, a introdução de rotas totalmente novas via transformação genética pela inserção de genes externos à planta. Estudos utilizando as duas linhas propostas têm demonstrado boas perspectivas no uso da fitorremediação.

O selênio, micronutriente essencial para animais e bactérias, é tóxico quando em níveis elevados. Sua importância para as plantas ainda não está esclarecida. Entretanto, algumas algas Chlamidomonas spp. de ancestralidade comum com plantas contém selenoproteínas (NOVOSELOV et al., 2002). Embora algumas plantas hiperacumuladoras tolerem selênio, em geral sua absorção nos tecidos é vista como potencialmente tóxica. A toxidez por selênio em plantas se deve à sua similaridade com sulfato, e proteínas envolvidas no transporte de sulfato e metabolismo de enxofre podem atuar em compostos análogos ao selênio. Quando selenato é assimilado via rota-sulfato, o selênio pode ser incorporado nos aminoácidos de enxofre como cisteína e metionina levando à formação de selenocisteína e selenometionina. A incorporação não-específica de selenocistéina em proteínas causa toxicidade (STADTMAN, 1990). 
CpNifS, proteína cloroplastídica em Arabidopsis thaliana, está envolvida no metabolismo de enxofre e de selênio (PILON-SMITS et al., 2002). CpNifS evita a incorporação de selênio em proteínas, protegendo as plantas da toxidez. Trabalho usando plantas transformadas de Arabidopsis com CpNifS e análises de microarranjos foi realizado para entender como a superexpressão da proteína pode afetar a tolerância e o acúmulo de selênio em plantas, bem como investigar mudanças no transcriptoma quando plantas crescem na presença de selenato (HOEWYK et al., 2005). Foi observado maior acúmulo de selênio na parte aérea das plantas transgênicas que nas plantas nãotransformadas. Essas se mostraram mais hábeis em tolerar selenato devido sua capacidade de mover selênio e evitar sua incorporação em proteínas, metabolizando selenocistéina em $\mathrm{Se}^{0} \mathrm{e}$ alanina. A reduzida incorporação preveniu a toxidez nas plantas, incrementando a tolerância ao selênio (HOEWYK et al., 2005).

O mercúrio, um dos sérios poluentes ambientais, é liberado para o ambiente mediante mineração do ouro, atividades industriais, queima de combustível fóssil e resíduos médicos. Uma vez no ambiente, o elemento mercúrio e íons $\left(\mathrm{Hg}^{2+}\right)$ são convertidos por bactérias redutoras de sulfato ao composto extremamente tóxico metilmercúrio (PILON-SMITS e PILON, 2000). Plantas, geralmente, não volatilizam mercúrio e não podem detoxificar metilmercúrio. O acúmulo de mercúrio em seus tecidos pode ser tóxico para a vida silvestre. A tolerância ao mercúrio é normalmente baixa e, portanto, a fitorremediação pode ser limitada pela planta tolerante (PILON-SMITS e PILON, 2000).

Estudo com mercúrio evidenciou que a introdução de rota metabólica externa à planta (bacteriana) permitiu a conversão de metilmercúrio tóxico ao elemento mercúrio (volátil em plantas). Esse processo envolve a enzima organomercurial lyase (codificada pelo gene MerB), a qual converte metilmercúrio a $\mathrm{Hg}^{2+}$. A segunda enzima envolvida nesse processo é a mercúrio redutase (codificada pelo gene MerA), responsável por reduzir $\mathrm{Hg}^{2+}$ ao elemento mercúrio usando NADPH como doador de elétrons (PILON-SMITS e PILON, 2000).

A transformação de Arabidopsis, inserindo rota bacteriana para conversão de mercúrio com promotor constitutivo 35S, resultou em plantas transgênicas altamente tolerantes a $\mathrm{Hg}^{2+} \mathrm{e}$ capazes de volatilizar mercúrio (MEAGHER et al., 2000). Plantas transgênicas, expressando MerB, foram significativamente mais tolerantes à metilmercúrio e a outros organomercuriais quando comparadas àquelas não-transformadas. Essas plantas converteram metilmercúrio a $\mathrm{Hg}^{2+}$, o qual é cem vezes menos tóxico.

O acetato de fenil mercúrio (PMA) é importante porque atua no cloroplasto. Trabalho integrando um nativo operon com genes MerA e MerB, codificando para mercúrico íon redutase e organomercurial lyase, respectivamente, no genoma do cloroplasto de fumo num único evento de transformação foi realizado (RUIZ et al., 2003). Os dois clones transgênicos cresceram bem na concentração de até $100 \mu \mathrm{M}$ de PMA, sobrevivendo inclusive na maior dose testada. Para a planta não-transformada $100 \mathrm{e}$ $200 \mu \mathrm{M}$ de PMA foram letais, a qual sobreviveu com dificuldade a $50 \mu \mathrm{M}$ de PMA.

O uso da transformação do cloroplasto para incrementar a fitorremediação de mercúrio é particularmente benéfico porque evita escape de transgenes via pólen para plantas daninhas ou culturas. A transformação de cloroplastos também pode encontrar aplicação em outros metais que afetam sua função (RUIZ et al., 2003).

O complexo enzimático que envolve citocromo P-450 oxigenases e glutationa S-transferases (GST) detoxifica compostos xenobióticos em plantas. GST são candidatas para o desenvolvimento de transgênicos visando rápida degradação de poluentes herbicidas nos campos agrícolas (ARMSTRONG, 1998; DIXON et al., 1998; EDWARDS, DIXON e WALNOT, 2000). Cloroacetanilidas são herbicidas amplamente utilizados para o controle de Poaceae e dicotiledôneas em diversas culturas, como milho e soja. O alacloro, herbicida pré-emergente, é absorvido pelas raízes e translocado à parte aérea das plantas pelo apoplasto. Estudos apontam a biotransformação de alacloro em plantas realizada por GST. Em milho, a conjugação com GST constitui a maior rota de metabolismo dos herbicidas cloroacetanilidas. A isoenzima GST 1 de milho tem sido amplamente pesquisada por sua habilidade em detoxificar vários xenobióticos (ROSSINI et al., 1996). Plantas 
de fumo transformadas com o gene de GST de milho mostraram maior tolerância ao alacloro quando comparadas às não-transgênicas (KARAVANGELI et al., 2005).

O herbicida atrazina, utilizado desde a década de 50, é levemente hidrofílico e pode contaminar águas. Em muitos países da Europa, por exemplo, seu uso está proibido. A metabolização da atrazina em plantas ocorre por hidroxilação, dealquilação e conjugação com glutationa. N-dealquilação é catalizada por citocromo P-450 monoxigenase, também encontrada em mamíferos e envolvida no metabolismo de xenobióticos. Desse modo, KAWAHIGASHI et al. (2005) compararam a habilidade de plantas de arroz transgênico, expressando P-450 de humanos na fitorremediação de áreas contaminadas com atrazina. Foi observado que o resíduo de atrazina no solo com plantas transgênicas decresceu ( $38,1 \%$ do valor do solo sem plantas). Portanto, é possível a remoção de atrazina mais rapidamente em solos com plantas transformadas (KAWAHIGASHI et al., 2005).

\section{BENEFÍCIOS E LIMITAÇÕES}

Dentre as vantagens da fitorremediação pode-se destacar seu custo reduzido quando comparado aos demais métodos de despoluição e a opção de tratamento natural in situ. Sua capacidade de múltiplos objetivos também é vantajosa (pode-se fitorremediar mais de um poluente no mesmo local), bem como a atratividade para o público leigo em função de ser vista como "tecnologia verde".

A fitotoxicidade de muitas espécies de plantas precisa ser melhor estudada para verificar até que níveis podem suportar os poluentes. O tempo constitui outra limitação em razão da dependência do ciclo de crescimento e desenvolvimento da planta, assim como a contaminação da cadeia alimentar que pode ocorrer caso as plantas não sejam cuidadosamente isoladas. Além disso o conhecimento sobre o potencial de muitas espécies de plantas é limitado e exige integração interdisciplinar para o aproveitamento real dessa nova tecnologia.

\section{CONSIDERAÇÕES FINAIS}

O uso de plantas e seus associados para a limpeza de áreas poluídas, a fitorremediação, é uma tecnologia potencial que pode ser adotada de acordo com o tipo do poluente. A integração de diversas áreas de pesquisa permitirá que os avanços obtidos tornem essa tecnologia disponível para o tratamento de locais contaminados pela poluição ambiental. Pesquisas envolvendo fitorremediação representam oportunidades de desenvolvimento de tecnologia nacional mediante estudos voltados para os diversos problemas ambientais brasileiros.

\section{ABSTRACT}

\section{PHYTOREMEDIATION: PLANTS LIKE AGENTS OF DESPOLUTION?}

The objective of this paper was to review the aspects of phytoremediation and the possibility of its application to decontamination of polluted areas caused by human activities. Were discussed several aspects as phytoremediation methods, physiological process involved, properties of used plants, the relation with biotechnology and advantages and disadvantages of this new technology. Industrialization and the use of chemicals in agriculture cause pollution, and the cleanning of potentially toxic compounds became difficult due to different class and types of chemicals. Other aspect that burdens the recovery of an area is the expensive cost of traditional methods used to clean the pollution. As a result, the phytoremediation is a technology that is attracting world interest and presents a potential to be used in Brazil. Scientific research has selected several species with potential to decontaminate polluted areas and biotechnology has improved the decontaminating ability of other plants.

KEY-WORDS: PHYTOREMEDIATION; ENVIRONMENTAL POLLUTION; HERBICIDES; METALS; HYPERACCUMULATOR PLANTS. 


\section{REFERÊNCIAS}

1 ARMSTRONG, R.N. Mechanistic imperatives for the evolution of glutathione transferases. Current Opinion Chemistry Biology, London, v.2, n.5, p.618-623, 1998.

2 BARAC, T. et al. Engineered endophytic bacteria improve phytoremediation of water-soluble, volatile, organic pollutants. Nature Biotechnology, London, v.22, n.5, p.583-588, 2004.

3 BEHKI, R. M.; KHAN, S. U. Degradation of atrazine by Pseudomonas: N-dealkylation and dehalogenation of atrazine and its metabolites. Journal of Agricultural and Food Chemistry, Washington, v.34, n.4, p.746-749, 1986.

4 BEHKI, R. M.; TOPP, E.; DICK, W.; GERMON, P. Metabolism of the herbicide atrazine by Rhodococcus strains. Applied and Environmental Microbiology, Washington, v.59, n.6, p.1955-1959, 1993.

5 BIOTECH. Método utiliza plantas para limpar solos contaminados com metais pesados. Disponível em: http:// www.cib.org.br. Acesso em: 03 mar. 2006.

6 CETESB. Relação de áreas contaminadas. Disponível em: http://www.cetesb.sp.gov.br/Solo/areas contaminadas/ relacao areas.asp. Acesso em: 19 set. 2007.

7 CHANG, P.C. et al. Uranium accumulation of crop plants enhanced by citric acid. Environmental Geochemistry and Health, Dordrecht, v.27, n.5-6, p.529-538, 2005.

$8 \mathrm{CHEN}$, B. et al. Effects of the mycorrhizal fungus Glomus intraradices on uranium uptake and accumulation by Medicago trunculata L. from uranium-contaminated soil. Plant and Soil, Dordrecht, v.275, n.1-2, p.349-359, 2005.

9 COSTA, S.M.S.P. da. Avaliação do potencial de plantas nativas do Brasil no tratamento de esgoto doméstico e efluentes industriais em "wetlands" construídos. Campinas, 2004. 119 p. Tese (Doutorado em Engenharia Química), Faculdade de Engenharia Química, Universidade Estadual de Campinas.

10 DAWSON, T.E.; EHLERINGER, J.R. Streamside trees do not use stream water. Nature, London, v.350, n.6316, p.335337, 1991.

11 DIXON, D.P. et al. Glutathione-mediated detoxification systems in plants. Current Opinion in Plant Biology, London, V.1, n.3, p.258-266, 1998.

12 EDWARDS, R.; DIXON, D.P.; WALNOT, V. Plant glutathione S-transferases: enzymes with multiple functions in sickness and in health. Trends in Plant Science, London, v. 5, n.5, p.193-198, 2000.

13 GRATÃO, P.L. et al. Phytoremediation: green technology for the clean up of toxic metals in the environment. Brazilian Journal of Plant Physiology, Brasília, v.17, n.1, p.53-64, 2005.

14 GREENPEACE. Notícias. Disponível em: http://www.greenpeace.org.br. Acesso em: 12 nov. 2006.

15 GÜNTHER, T.; DORNBERGER, U.; FRITSCHE, W. Effects of ryegrass on biodegradation of hydrocarbons in soil. Chemosphere, Oxford, v.33, n.2, p.203-215, 1996.

16 HOEWYK, D.V. et al. Overexpression of AtCpNifs enhances selenium tolerance and accumulation in Arabidopsis. Plant Physiology, Rockville, v.139, n.3, p.1518-1528, 2005.

17 HUANG, J.W. et al. Phytoremediation of uranium-contaminated soils: role of organic acids in triggering uranium hyperaccumulation in plants. Environmental Science Technology, Washington, v.32, n.13, p.2004-2008, 1998.

18 JONER, E.J.; BRIONES, R.; LEYVAL, C. Metal-binding capacity of arbuscular mycorrhizal mycelium. Plant and Soil, Dordrecht, v,226, n.2, p.227-234, 2000.

19 KAIMI, E. et al. Ryegrass enhancement of biodegradation in diesel-contaminated soil. Environmental and Experimental Botany, Oxford, v.55, n.1-2, p.110-119, 2006.

20 KARAVANGELI, M. et al. Development of transgenic tobacco plants overexpressing maize glutathione S-transferase I for chloroacetanilide herbicides phytoremediation. Biomolecular Engineering, Amsterdam, v.22, n.4, p.121-128, 2005.

21 KAWAHIGASHI, H. et al. Transgenic rice plants expressing human CYP1A1 remediate the triazine herbicides atrazine and simazine. Journal of Agricultural and Food Chemistry, Washington, v.53, n.22, p.8557-8564, 2005.

22 LEVANON, D. Roles of fungi and bacteria in the mineralization of the pesticides atrazine, alachlor, malathion and carbofuran in soil. Soil Biology \& Biochemistry, Oxford, v.25, n.8, p.1097- 1105, 1993.

23 LI, Y-M. et al. Development of a technology for commercial phytoextraction of nickel: economic and technical considerations. Plant and Soil, Dordrecht, v.249, n.1, p.107-115, 2003. 
24 MA, L.Q.; KOMAR, K.M.; TU, C. A fern that hyperaccumulates arsenic - hardy, versatile, fast-growing plant helps to remove arsenic from contaminated soils. Nature, London, v.409, n.6820, p.579, 2001.

25 McCUTCHEON, S.C.; SCHNOOR, J.L. Overview of phytotransformation and control of wastes. In: McCUTCHEON, S.C.; SCHNOOR, J.C. (eds). Phytoremediation: transformation and control of contaminants. New York: Wiley, 2003. p.3-58.

26 MEAGHER, R.B. et al. Engineered phytoremediation of mercury pollution in soil and water using bacterial genes. In: TERRY, N.; BANUELOS, G. (eds). Phytoremediation of contaminated soil and water. Boca Raton: CRC Press, 2002. p.201-221.

27 NASCIMENTO, R.A. Desempenho de reator anaeróbico de manta de lodo utilizando efluentes líquidos de indústrias alimentícias. Campinas, 1996. 112 p. Dissertação (Mestrado em Engenharia Civil) - Faculdade de Engenharia Civil, Universidade Estadual de Campinas.

28 NOVOSELOV, S.V. et al. Selenoproteins and selenocysteine insertion system in the model plant cell system, Chlamydomonas reinhardtii. EMBO Journal, Oxford, v.21, n.14, p.3681-3693, 2002.

29 PILON-SMITS, E. Phytoremediation. Annual Review of Plant Biology, Palo Alto, v.56, p.15-39, 2005.

30 PILON-SMITS, E.; PILON, M. Breeding mercury-breathing plants for environmental cleanup. Trends in Plant Science, London, v.5, n.6, p.235-236, 2000.

31 PILON-SMITS, E.A.H. et al. Characterization of a NifS-like chloroplast protein from Arabidopsis. Implications for its role in sulfur and selenium metabolism. Plant Physiology, Rockville, v. 130, n.3, p.1309-1318, 2002.

32 PLETSCH, M.; CHARLWOOD, B.V.; ARAÚJO, B.S. de. Fitorremediação de águas e solos poluídos. Biotecnologia, Ciência \& Desenvolvimento, Brasília, v.2, n.11, p.26-29, 1999.

33 PROCÓPIO, S.O. et al. Potencial de espécies vegetais para a remediação do herbicida trifloxysulfuron-sodium. Planta Daninha, Viçosa, v.23, n.1, p.9-16, 2005.

34 RASKIN, I. et al. Bioconcentration of heavy metals by plants. Current Opinion in Biotechnology, London, v.5, n.3, p.285-290, 1994.

35 ROSSINI, L. et al. Characterization of glutathione S-transferase isoforms in three maize inbred lines exhibiting differential sensitivity to alachlor. Plant Physiology, Rockville, v. 112, n.4, p.1595-1600, 1996.

36 RUFYIKIRI, G. et al. Uranium uptake and translocation by the arbuscular mycorrhizal fungus, Glomus intraradices, under root-organ culture conditions. New Phytologist, Oxon, v.156, n.2, p.275-281, 2002.

37 RUFYIKIRI, G.; THIRY, Y.; DECLERCK, S. Contribution of hyphae and roots to uranium uptake and translocation by arbuscular mycorrhizal carrot roots under root-organ culture conditions. New Phytologist, Oxon, v.158, n.2, p.391-399, 2003.

38 RUIZ, O.N. et al. Phytoremediation of organomercurial compounds via chloroplast genetic engineering. Plant Physiology, Rockville, v.132, n.3, p.1344-1352, 2003.

39 STADTMAN, T.C. Selenium biochemistry. Annual Review of Biochemistry, Palo Alto, v.59, p.111-127, 1990.

40 WILLIAMS, J.B. Microbial factors affecting the design and operation of a gravel bed hydroponic sewage treatment system. Portsmouth, 1993. p.112. Dissertation (PhD) - University of Portsmouth. 